\title{
THE EFFECT OF CARDIAZOL CONVULSIONS ON THE SO-CALLED "BULBOCAPNINE CATATONIA" IN THE MONKEY
}

\author{
BY \\ ALEXANDER KENNEDY \\ Maudsley Hospital, London, England, and the Psychobiological Laboratory, the Johns Hopkins \\ Hospital, Baltimore, U.S.A. \\ (Received 21st December, 1938) \\ LITTLE is yet understood as to the mode of action of the cardiazol convulsion \\ in schizophrenic states and especially in the catatonic forms in which this \\ method of treatment seems (v. Meduna, 1934) to be most effective. A possible \\ method of approach to this problem lies in the study of the convulsion as it \\ affects the animal, and of its effect on artificially induced states having features \\ in common with catatonia. The experiments to be described were undertaken \\ with the object of determining the effect of cardiazol convulsions on the \\ hypokinetic state produced by bulbocapnine in monkeys, and more especially \\ on the components of that state which have an objective resemblance to the \\ catalepsy of catatonic stupor. \\ It has been shown (Richter and Paterson, 1931) that one of the features of \\ the state produced by bulbocapnine in the adult monkey is a reappearance of \\ the neonatal grasp-reflex (Richter, 1931). By measuring the time during which \\ the animals will hang from a bar of standard dimensions, an indication was \\ obtained of the intensity of action of the drug at different periods after its \\ administration. Although the length of these hanging-times does not neces- \\ sarily vary quantitatively with the intensity of the cataleptoid phenomena, the \\ data obtained in this way serve to provide a graphic record with which the time- \\ relations of the other effects observed may be compared, and as such they were \\ used in the present work.
}

\section{Technique}

The monkeys used were five adults of the Macacus rhesus species, each weighing about 3.5 kilos. The apparatus used for determining the time during which the animals would hang consisted of a brass rod $\frac{5}{8}$ in. in diameter, held by two uprights $4 \mathrm{ft} .6 \mathrm{in}$. above an iron frame, over which a net was stretched. The hanging response was tested in one hand at a time, the other hand being tied, as were the feet, so that they could not be used to grip the bar. At each trial the animal was held up by the head while the palm of the free hand was allowed to come into contact with the bar, when, if the reflex was present, grasping took place. The animal was then released 
and allowed to hang without support. The time from the moment when support was withdrawn to the moment when the animal fell into the net was taken with a stopwatch and recorded as the hanging-time.

Although the monkeys used were old enough to have lost the neonatal grasp reflex, in some of them a slight reflex was present which caused them to hang for a few moments. Their hanging times became gradually less at subsequent trials and finally disappeared and did not return. The presence of the grasp reflex was tested for on a number of occasions before the animals were used in an experiment, as well as at the commencement of each trial. No animal was used in an experiment if it did not, on being put to the bar, at once let go and try actively to escape. With the hangingtimes as ordinates and the time in minutes as abscissa, a graphic record was made in each case (Fig. 1).

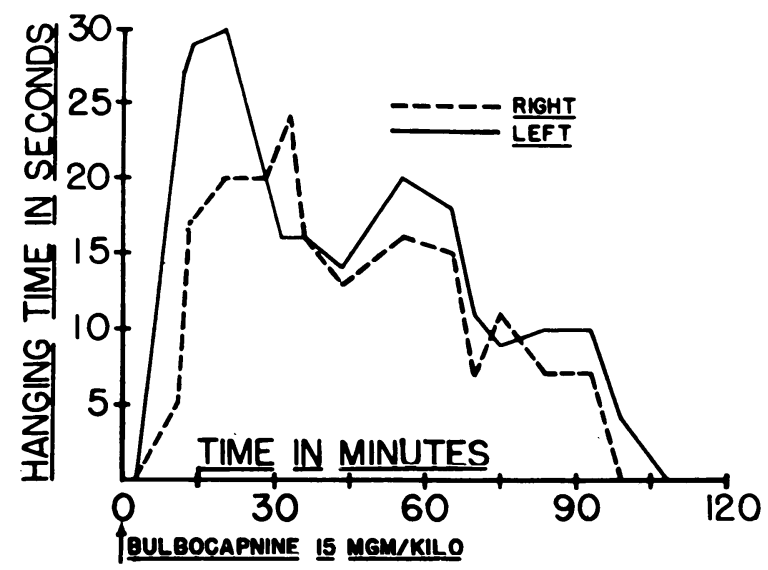

Fig. 1.-Graph showing hanging-times in right and left hands of the same monkey at different periods after the injection of $50 \mathrm{mg}$. of bulbocapnine. (Weight of animal, $3.5 \mathrm{kilos}$.)

Throughout each experiment, in addition to the hanging-time records, a continuous record was kept of the state of the animals as seen by direct observation and examination at different periods after the injections. A number of motion-pictures were also made at critical phases in order to allow of a more accurate analysis of postural changes and movements, as well as to make a permanent record of the more important features which could be examined at leisure. The presence of tremors and the presence of catalepsy and their duration were recorded on the graphic records as horizontal lines. Tremor was said to be present when a coarse tremor of the head and limbs appeared with a rate of about five per second, and catalepsy was recorded only when the animal would maintain unnatural positions against gravity for several minutes, was completely without spontaneity, and moved only a minimum in response to strong stimuli. This condition was rarely present when bulbocapnine alone was used and then only for short periods.

The experiments were carried out in the mornings, no food having been given since the previous night ; in order to keep conditions constant, noise was reduced to a minimum and the monkeys handled as little as possible. Readings were taken approximately every 10 minutes and were continued for three readings after the animal had ceased to grasp. It was found that the most constant results were obtained with a dosage of $15 \mathrm{mg}$. per kilo, and the curves so obtained were closely similar in each case (Fig. 2).

The bulbocapnine used was obtained in ampoules containing a 10-per cent. solution of the hydrochlorate from Messrs. Merck, and was given subcutaneously. The cardiazol was given as a 10-per cent. solution buffered to $p \mathrm{H} 8$ by the addition of $0 \cdot 1$ 
per cent. of sodium dihydrogen phosphate, as described elsewhere for clinical use (Kennedy, 1937). This was given intravenously as rapidly as possible in order to reduce the dosage to a minimum in view of the speed with which the drug disappears from the circulation.

The effects of bulbocapnine were first established in five monkeys, data being obtained on the grasp-reflex changes, motor responses, and general behaviour as

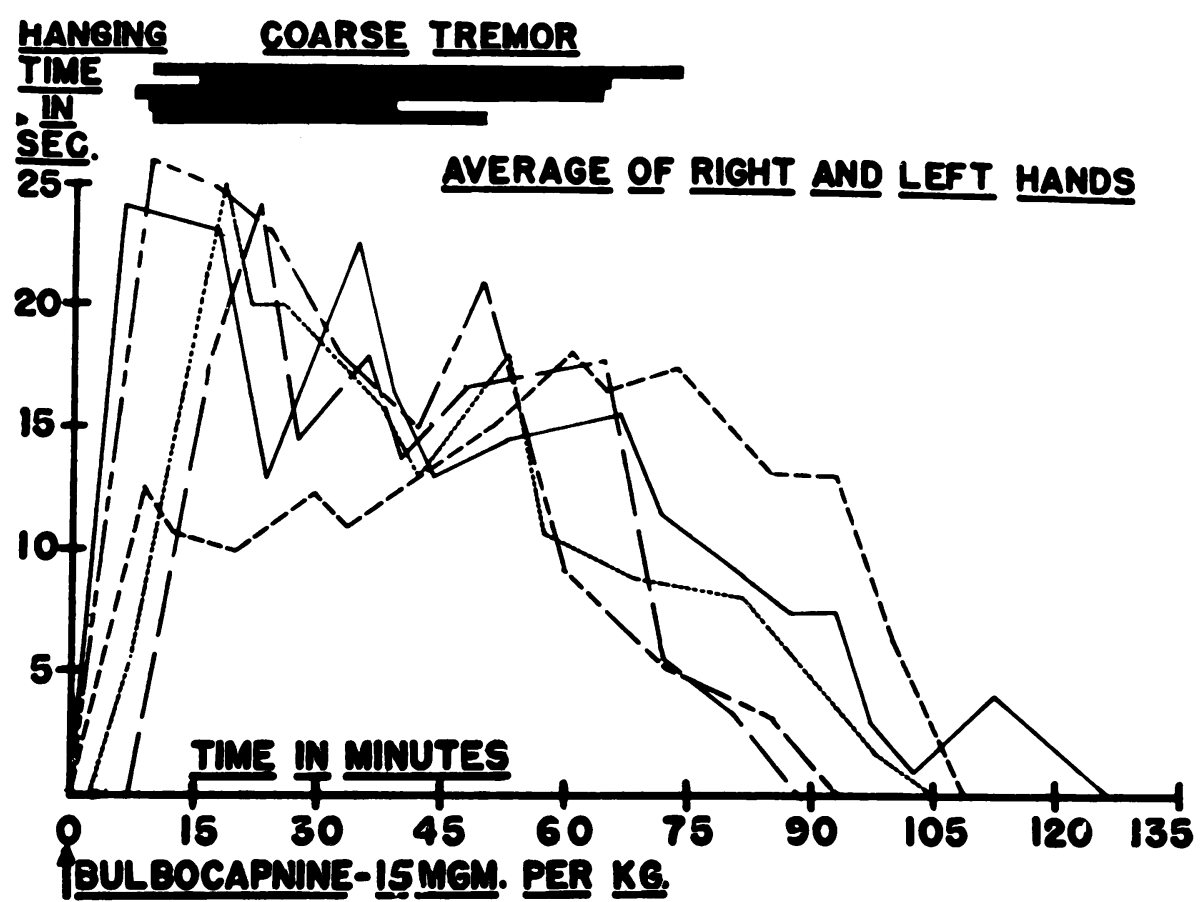

Fig. 2.-Curves showing hanging-times of five monkeys at different periods after injection of the same dose of bulbocapnine. (Periods during which tremors were present are represented by the horizontal lines at the top of the figure. The times shown are the average hangingtimes for the two hands. Two of these animals were used in the present series of experiments.)

described. One week later, when, as shown by activity records, appetite, and weight, the animals were in the same condition, a single convulsant dose of cardiazol was given and the effects noted in the same way. One week after this, convulsions were induced with the same dose of cardiazol, given when the effect of bulbocapnine was at its height ; and, finally, two of the animals were given a further trial with bulbocapnine alone in order to find whether it still produced the same results in a monkey that had had two convulsions.

\section{Results}

Effect of bulbocapnine alone.-In the five monkeys used, the hanging-curves and descriptive data were essentially similar and the following features were common to all the records, a typical example of which will be given in detail later. When $15 \mathrm{mg}$. per kilo of bulbocapnine was given, the grasp reflex appeared within 5 to 15 minutes after the injection in all the animals, by which time they had ceased to move about and had all assumed the "Penseur de Rodin " attitude and showed gross tremors of the neck and extremities. These 
tremors had an average frequency of four to five per second. None of the animals showed any inclination to move towards food which was put in front of them, and when pushed they would move only a few inches before coming to rest. When a limb was raised, after perhaps a few moments of immobility, it would be slowly lowered and never held against the action of gravity for long. All five monkeys, however, if placed on their backs, would remain still with the extremities in the air for about a minute before slowly taking up a recumbent position.

Eye movements were of normal rapidity, but if the animals' attention was attracted by a sound at one side, their eyes would turn in the direction of the sound before the head moved, if it moved at all. Tendon reflexes were present at all stages and slight rigidity of the "cogwheel "variety was present in the flexors of the arms. During the first 25 minutes excessive salivation and usually dribbling were present. The tendency to keep the limbs in the same posture was just as marked when the tremors had practically disappeared as when they were most evident, but this cataleptic tendency invariably disappeared at least 10 minutes before the animals ceased to hang.

The hanging-time was taken for each hand separately, and when this was done at regular intervals of 10 minutes it was found that the times were remarkably uniform in the two hands (Fig. 1). For simplicity in expressing the results, the mean time for the two hands is shown in subsequent figures. As may be seen in the figures (especially Fig. 2) the hanging times were usually greatest at the commencement and then remained at roughly the same level for about 70 minutes, after which they gradually decreased.

Effect of cardiazol convulsions alone.-Preliminary experiments established that the ideal dose was $0 \cdot 1$ c.c. of the 10 per cent. solution per kilo of body weight, given intravenously as rapidly as possible. This is roughly equivalent to the average dose used in therapeutic convulsions in man. It was found that with 0.08 c.c. an excitable state was produced in which there was much twitching but no convulsions and that when 0.2 c.c. was given to two of the animals a status epilepticus appeared which lasted for over two hours. Within 10 seconds of the injection, typical epileptiform convulsions appeared with a tonic phase of 3 to 10 seconds followed by a short clonic phase which lasted a little over a minute. In the 3 minutes which followed the onset of the fit, a transient hanging response was found in all the animals, but it was of only a few seconds' duration and irregular in appearance, and after this period they behaved normally in every way.

Effect of a Cardiazol convulson given during the action of bulbocapnine.The same dose of bulbocapnine as was used in the previous experiments was given again to the same animals and the usual effects, of salivation, tremor, immobility, and hanging response, were observed. About 25 minutes after the bulbocapnine was given, when, as seen in Fig. 3, the hanging time was at its highest level, the cardiazol was injected, $0 \cdot 1$ c.c. per kilo being given as before. The convulsions produced were similar in all respects to those which occurred when no bulbocapnine had been given. It was especially noticeable that in the period immediately following the convulsion the coarse tremors 
were absent and the muscles were flaccid until the animals began to show evidence of awareness of their surroundings. After the convulsions they were rather drowsy for about 10 minutes, after which their condition came to resemble that before the convulsion. Catalepsy, when present at all, was very slight at this stage.

At a time varying from 20 to 35 minutes after the convulsion, when the tremors were beginning to diminish, a remarkable change came quite rapidly over all the animals. Eye movements ceased altogether, and the animals stared in front of them with eyes wide open, the occasional blinking seen in the bulbocapninized animal being absent. At the same time there was a change of muscle tone which allowed of the limbs being placed in any position without hindrance from rigidity, and a very profound cataleptic state developed in which

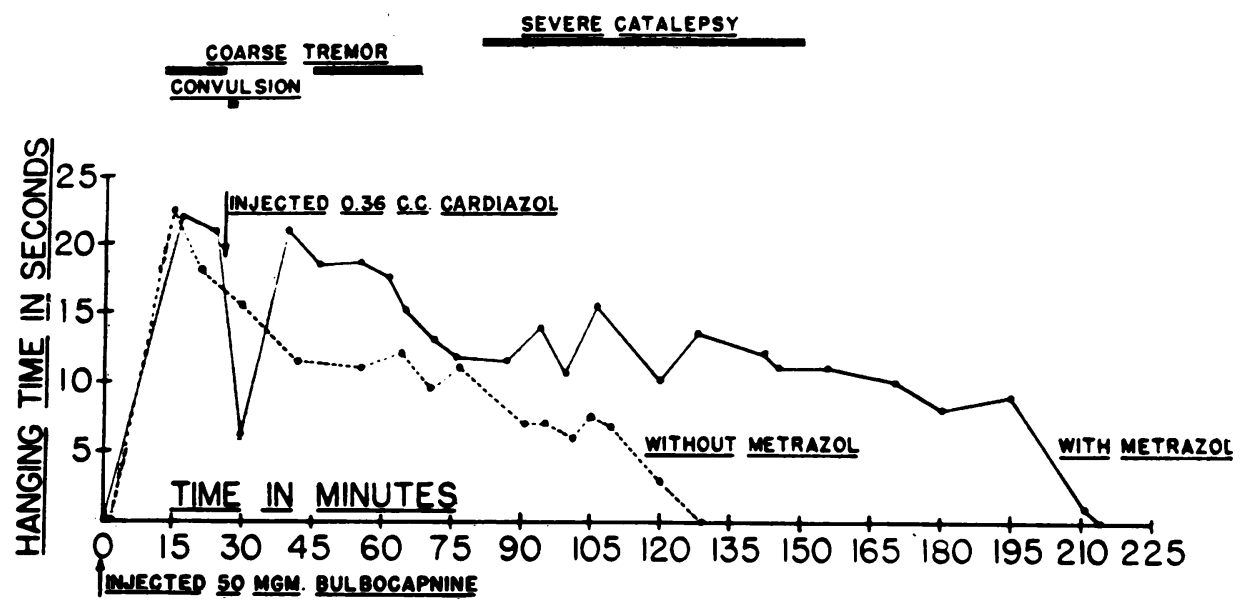

Fig. 3.-Two hanging-curves from the same monkey showing the effect of bulbocapnine alone (interrupted line) and the effect of inducing a convulsion with cardiazol when the effect of the bulbocapnine was at its height. Note the prolongation of the hanging period and the appearance of well-marked catalepsy.

the animals could be placed in any posture, where they would remain until moved. When pushed over, there was no attempt at righting, and when they fell from the bar after hanging, the animals remained in the position in which they fell, as if inanimate. The catalepsy was far more profound than that seen with bulbocapnine alone, and fully satisfied the criteria of Ferraro and Barrera (1931). This cataleptoid state persisted for from 25 to 70 minutes in the different animals, and during this period the hanging times remained roughly at the same level. The condition then disappeared quite rapidly and the hanging times at once became shorter. This is well seen in Fig. 3, where the duration of the deep catalepsy is represented by a horizontal line, at the termination of which the hanging times are seen rapidly to become shorter. The animals were always slow and inactive after these experiments, in contrast to the experiments with bulbocapnine and with convulsions alone, and activity records showed that they did not regain their former level for 24 to 48 hours.

In order to illustrate this general description, the experimental data and 
graphic records from one of the five animals are given in detail (see p. 122), the results for the others being summarized in Fig. 4. In this table it can be seen that the period during which the hanging response was present was greatly prolonged in all the animals, being roughly half as long again as when no convulsion was given.

\begin{tabular}{|c|c|c|c|c|}
\hline \multirow{2}{*}{$\begin{array}{l}\text { NO. OF } \\
\text { MONKEY }\end{array}$} & \multicolumn{2}{|c|}{ MEAN DURATION OF GRASP-REFLEX } & \multirow{2}{*}{ INCREASE } & \multirow{2}{*}{$\begin{array}{l}\text { RATIO OF } \\
\text { INCREASE }\end{array}$} \\
\hline & $\begin{array}{c}\text { BULBOCAPNINE } \\
\text { ONLY }\end{array}$ & $\begin{array}{c}\text { WITH } \\
\text { CONVULSION }\end{array}$ & & \\
\hline $\begin{array}{l}90 \\
93 \\
95 \\
96 \\
98\end{array}$ & $\begin{array}{r}124 \\
77 \\
60 \\
71 \\
90\end{array}$ & $\begin{array}{r}203 \\
113 \\
94 \\
119 \\
135\end{array}$ & $\begin{array}{l}79 \\
36 \\
34 \\
38 \\
45\end{array}$ & $\begin{array}{l}1.64 \\
1.44 \\
1.57 \\
1.53 \\
1.50\end{array}$ \\
\hline
\end{tabular}

Fig. 4.-Table showing increase in hanging-time due to cardiazol convulsions.

\section{Discussion}

From the experiments described it is evident that the convulsions induced by injections of cardiazol in the monkey are comparable in all details with the therapeutic convulsions observed in the human subject. Not only is the dosage roughly the same in proportion to the body-weight, but the time-relations of the convulsion itself and the effects of non-convulsive doses are closely similar. In view of this very close similarity, the effects of overdose are of considerable clinical interest, the amount sufficient to induce status epilepticus in the monkey being roughly equivalent to an injection of 14 c.c. of cardiazol solution in a man of average weight.

The hypokinetic state produced in monkeys by the action of bulbocapnine is made up of a number of component phenomena, some of which are common to it and to catatonic stupor. Such features are the immobility, lack of motor initiative, and the tendency for the limbs to remain in abnormal positions when so placed, i.e. catalepsy. Other features, such as stereotypy and mannerisms, have been described as common to the two conditions, especially by de Jong and Baruk (1930), but they are less constant and involve an interpretation of the animal's behaviour in clinical terms. Other features, such as bradykinesis, tremor, and salivation, emphasized by Schaltenbrand, suggest a resemblance to an extrapyramidal syndrome. The effect of cardiazol convulsions is to increase some of the components of this composite state, to decrease others, and to leave others practically unchanged. The catalepsy is very noticeably increased in the period after the convulsion, as is the hanging-time, which to some extent acts as a measure (Richter, 1931) of its intensity, while during the actual convulsion tremor is absent, nor does it fully return in the post-convulsive period. Thus the cataleptoid features are greatly increased while the signs resembling those of extrapyramidal dysfunction are decreased. This effect is similar to that seen 
when carbon dioxide is given in high concentration to the animal under the influence of bulbocapnine (Paterson and Richter, 1933) and is in contrast to that of cocaine, which completely abolishes the catalepsy (Buchman and Richter, 1933) and, with it, the hanging-response.

That the hanging-response is not due solely to the presence of catalepsy is shown by the fact that it remains when the catalepsy has gone (Fig. 3). It has been shown (Richter and Paterson, 1932) that a variety of substances, most of them cerebral depressants, cause the response to appear in the monkey, and, though many of these induce an akinetic state, none produces cataleptoid phenomena comparable with those induced by bulbocapnine. The hangingtimes are, however, greatest when catalepsy is present.

In these experiments convulsions alone produced only a transient hanging response. It would therefore seem likely that in these animals in the postconvulsive period there was a phase of lowered activity of a part at least of the nervous system, which produced a specific effect in intensifying bulbocapnine catalepsy and a more general one in causing an additional increase in the hangingtime. That the part of the nervous system most affected in this specific action is the cortex is suggested by the fact that in the post-convulsive period the tremor is greatly reduced and usually abolished. It has been shown that unilateral decortication (Ferraro and Barrera, 1932) and decerebration (Schaltenbrand, 1925) cause bulbocapnine tremors to disappear on the contralateral side, that is, that an intact cortex is essential for their production. In view of this it may be that a lowering of cortical activity after the convulsion balances the subcortical disturbance produced by bulbocapnine and thus abolishes the tremor. If, from its speed, its association with an attitude of flexion, salivation, and rigidity, the tremor seen in a bulbocapninized monkey can be taken to be of the same nature as that of post-encephalitic Parkinsonism, the effect would be comparable to the clinical abolition of these tremors in sleep or in amytal narcosis. It may thus be that the action of convulsion, in increasing the cataleptic component of the state produced by bulbocapnine, is due to a temporary depression of function at the cortical level which occurs in the postconvulsive period.

\section{Summary}

The effects of moderate doses ( $15 \mathrm{mg}$. per kilo) of bulbocapnine on monkeys are fairly uniform in different animals and in the same animal on different occasions.

The effect of cardiazol convulsions on the state produced by bulbocapnine was studied in five monkeys and compared by means of its effect on the graspreflex, on the cataleptoid phenomena, and on the general motor state of the animal.

The action of the convulsion is greatly to increase the cataleptic component of the state produced by bulbocapnine, producing a very marked cataleptic state, and to prolong the action of the drug both in its action in producing an akinetic state and in causing a reappearance of the neonatal grasp-reflex. 
These effects are not produced by the convulsion alone, which causes only a transient akinesis and appearance of the grasp-reflex.

No change was found in the animal's response to bulbocapnine after it had been given convulsions, and the same type of curve was produced by the graspreflex technique a week after a convulsion as was obtained a week before.

When a non-convulsive dose of cardiazol was given, an excited, irritable state was produced in the animals, with hyperkinetic movements, but no convulsions. When twice the minimum convulsant dose was given, status epilepticus resulted.

A theoretical interpretation of these results is advanced in the light of previous work.

This work was carried out during tenure of a Rockefeller Fellowship in Neuropsychiatry, the experiments being performed in the Psychobiological Laboratory at the Johns Hopkins Hospital through the courtesy of Dr. Curt P. Richter, to whom the writer is indebted for valuable advice and assistance.

\section{REFERENCES}

Buchman, E. F., and Richter, C. P. (1933). Arch. Neurol. Psychiat., 29, 499.

de Jong, H., and Baruk, H. (1930). La catatonie experimentale par la Bulbocapnine. Masson et Cie, Paris.

Ferraro, A., and Barrera, S. E. (1932). Experimental Catalepsy, State Hospitals Pr.

Kennedy, A. (1937). J. ment. Sci., 83, 609.

v. Meduna, L. (1934). Die Konvulsionstherapie der Schizophrenie, C. Marhold, Halle.

Paterson, A. S., and Richter, C. P. (1933). Arch. Neurol. Psychiat., 29, 231.

Richter, C. P. (1931). Arch. Neurol. Psychiat., 26, 784.

Richter, C. P., and Paterson, A. S. (1931). J. Pharmacol., 43, 677.

Richter, C. P., and Paterson, A. S. (1932). Brain, 55, 391.

Schaltenbrand, G. (1925). Pfiüg. Arch. ges. Physiol., 209, 643. (1929). Dtsch. Z. Nervenheilk., 108, 209.

\section{Protocol from One Animal}

Monkey No. 90 (weight 3.6 kilos)

\begin{tabular}{|c|c|c|c|c|}
\hline \multirow{3}{*}{$\begin{array}{c}\text { EFFECT of } \\
\text { Time, } \\
\text { mins. } \\
\text { zero }\end{array}$} & \multicolumn{3}{|c|}{ BULBOCAPNINE ALONE } & \multirow[b]{2}{*}{ Remarks } \\
\hline & $\begin{array}{r}\text { Avera } \\
\text { hanging- } t\end{array}$ & & & \\
\hline & 0 & . & .. & Normal activity. Tries to escape. Bulbocapnine $15 \mathrm{mg}$. \\
\hline 6 & 26 & . & . & $\begin{array}{l}\text { Gross tremors have appeared. Animal is still and in a } \\
\text { flexed attitude. Looks about without turning head. }\end{array}$ \\
\hline 17 & 23 & . & . & Bowed attitude. Head nodding and limb tremors at less \\
\hline 23 & 14 & . & . & Takes one pace forward when pushed. \\
\hline 28 & 13 & . & . & When arm is raised, slowly lowers it. \\
\hline $\begin{array}{l}34 \\
39\end{array}$ & $\begin{array}{l}22 \\
16\end{array}$ & $\begin{array}{l}\cdots \\
\cdots\end{array}$ & $\begin{array}{l}. \\
\ldots\end{array}$ & Pushed over, slowly rights himself. \\
\hline 44 & 13 & .. & $\ldots$ & Head bowed nearly to ground. No catalepsy. \\
\hline 52 & 14 & .. & . & Salivating freely. \\
\hline 57 & 11 & . & . & $\begin{array}{l}\text { Very still. Much less tremor. Pushed over, lies where } \\
\text { he fell. }\end{array}$ \\
\hline 67 & 15 & . & .. & $\begin{array}{l}\text { Got up very slowly. If limb is raised, slowly lowers it, } \\
\text { but does not return it quite to ground. Has ceased } \\
\text { salivating. }\end{array}$ \\
\hline 72 & 10 & .. & • & \\
\hline
\end{tabular}


Protocol From One Animal-(continued)

Monkey No. 90 (weight 3.6 kilos)

EFFECT OF BULBOCAPNINE ALONE

\begin{tabular}{|c|c|c|c|}
\hline $\begin{array}{l}\text { Time, } \\
\text { mins. }\end{array}$ & $\begin{array}{c}\text { Average } \\
\text { hanging-time } \\
\text { seconds }\end{array}$ & & Remarks \\
\hline 82 & . & . & Tremor gone. No catalepsy. \\
\hline 88 & 7 & . & \\
\hline 93 & $\cdots$ & $\cdots$ & \\
\hline 97 & . & .. & Moves slowly forward. \\
\hline 102 & . & .. & \\
\hline 107 & . & . & \\
\hline 112 & . & . & Moves slowly across room. \\
\hline 117 & . & - & Accepts food hesitantly. \\
\hline 122 & . & .. & Is quite active again. \\
\hline
\end{tabular}

EFFECT OF CARDIAZOL ALONE

\begin{tabular}{|c|c|c|c|c|}
\hline $\begin{array}{l}\text { Time, } \\
\text { mins. }\end{array}$ & $\begin{array}{l}\text { Avera } \\
\text { hanging- } \\
\text { second }\end{array}$ & me, & & Remarks \\
\hline zero & 0 & . & .. & 0.36 c.c. cardiazol solution given intravenously. \\
\hline 9 & & . & . & $\begin{array}{l}\text { Violent purposeless movements, followed by flexor spasms } \\
\text { and tonic convulsions. }\end{array}$ \\
\hline 13 & - & $\cdots$ & . & $\begin{array}{l}\text { After tonic phase of about } 3 \text { seconds, has violent clonic } \\
\text { flexor movements. }\end{array}$ \\
\hline 27 & 0 & . & $\cdots$ & $\begin{array}{l}\text { Clonic movements cease, but frequent twitching move- } \\
\text { ments occur. Monkey will not grasp bar. }\end{array}$ \\
\hline 80 & 0 & . & $\ldots$ & $\begin{array}{l}\text { Twitching movements have gradually become less. Eyes } \\
\text { closed. Holds bar momentarily. }\end{array}$ \\
\hline 101 & 0 & $\cdots$ & $\cdots$ & Moves limbs in voluntary fashion. Looks about. \\
\hline 105 & 8 & $\cdots$ & - & $\begin{array}{l}\text { Hangs for } 10 \text { seconds with right hand. On dropping, } \\
\text { lies still. }\end{array}$ \\
\hline 140 & 2 & $\cdots$ & & More active, tries to escape. \\
\hline 190 & 0 & . & $\cdots$ & $\begin{array}{l}\text { Will not hang ; appears completely recovered. Behaved } \\
\text { normally on return to cage afterwards. }\end{array}$ \\
\hline
\end{tabular}

EFFECT OF A CARDIAZOL CONVULSION GIVEN DURING THE ACTION OF BULBOCAPNINE

Time, Average

mins. hanging-time,

Remarks

$\begin{array}{rrrr}0 & 0 & \ldots & . \\ 16 & 22 & \ldots & . \\ 22 & 21 & \ldots & . \\ 25 & - & \ldots & . \\ 28 & 4 & \ldots & . \\ 38 & 21 & \ldots & . \\ 46 & 18 & \ldots & . \\ 54 & 18 & \ldots & . \\ 61 & 17 & \ldots & . \\ 69 & 12 & \ldots & . \\ 75 & 11 & \ldots & . \\ 87 & 11 & \ldots & . \\ 94 & 14 & \ldots & . \\ 99 & 10 & \ldots & . \\ 104 & 11 & \ldots & .\end{array}$

. Bulbocapnine given, $15 \mathrm{mg}$. per kilo subcutaneously.

. Tremors have commenced.

. Immobile and flexed.

- Cardiazol 0.36 c.c. Convulsion lasts 80 seconds.

. Tremor very slight. Animal immobile.

- Rather sleepy. Will not hold up raised arm.

. Tremor returning. Rights self when pushed.

. Tremor less marked.

. Tremor gone. Remains absolutely still.

. No catalepsy.

.

- Eyes half closed. Very still. Some fine tremor of upper extremity. Very slowly lowers raised limb.

- Animal has quite rapidly developed a very marked flexibilitas cerea and can be put into almost any position, from which no attempt is made to move. Will stay with lower extremities against wall and upper limbs on the ground. Remained with all limbs extended for several minutes and was then moved in order to be hung from bar.

.. On falling from bar, stays as it fell ; on being pushed, falls over and remains in exactly same position for 5 minutes. 
Protocol from One Animal-(continued)

Monkey No. 90 (weight 3.6 kilos)

EFFECT OF CARDIAZOL CONVULSION GIVEN DURING THE ACTION OF BULBOCAPNINE

$$
\begin{aligned}
& \text { Time Average } \\
& \text { mins. hanging-time } \\
& 120 \text { seconds } \\
& \begin{array}{lrrr}
125 & 11 & \cdots & \cdots
\end{array} \\
& \begin{array}{lllll}
130 & 13 & \ldots & \ldots & \text { Flexibilitas continues. Blinks when feint is made towards }
\end{array} \\
& \text { eyes. No reaction to food. Does not look about at }
\end{aligned}
$$

Animal was quiet for several hours after conclusion and did not eat.

\section{EfFect of Bulbocapnine alone}

A second trial of bulbocapnine alone showed almost identical results to the first, showing that the convulsions had no permanent effect on the animal's reaction to the drug. The hanging-curve produced was very similar to the first and no true catalepsy was obtained. The effects of bulbocapnine and bulbocapnine-cardiazol on the hanging-response in this animal are represented graphically in Fig. 3. 